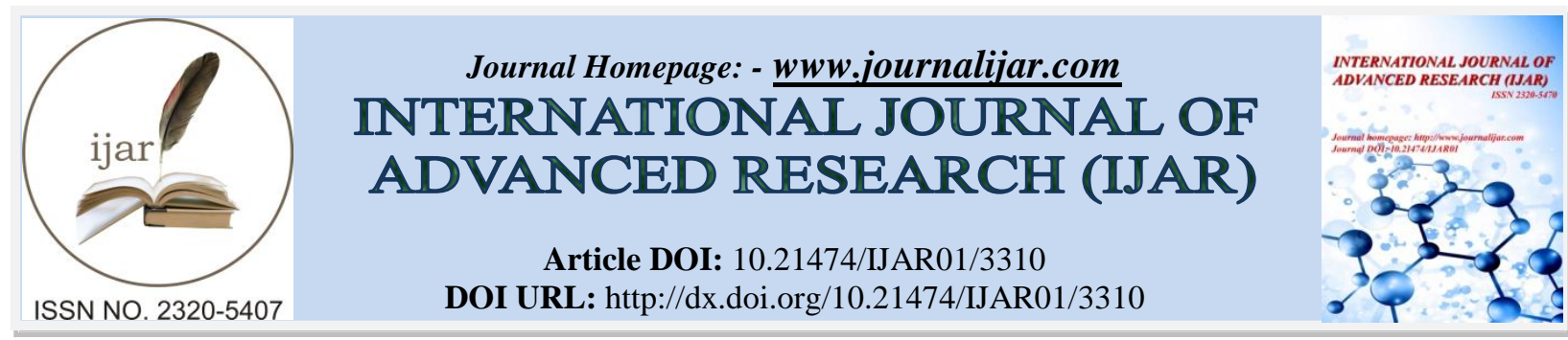

RESEARCH ARTICLE

\title{
NUMERICAL SIMULATION ON PERFORMANCE OF A LOW SPEED CENTRIFUGAL COMPRESSOR.
}

\section{S. M. Swamy ${ }^{1}$ and V. Panndurangadu ${ }^{2}$.}

1. Assistant Professor, Department of Mechanical Engineering, GNITS, Shaikpet, Hyderabad-500104, India.

2. Professor, Department of Mechanical Engineering, JNTUA, Ananthapuramu -515002, A.P, India.

\section{Manuscript Info}

Manuscript History

Received: 30 December 2016

Final Accepted: 29 January 2017

Published: February 2017

Key words:-

Centrifugal compressor, Partial shroud,

Flow Coefficient, Tip Clearance.

\begin{abstract}
The present computational investigation deals with performance improvement of a low speed centrifugal compressor by inexpensive partial shroud near the rotor blade tip. Computational study of centrifugal compressor is carried out with finite volume method upwind scheme using ANSYS CFX-15.0 software are carried for four flow coefficients $\varphi=0.12,0.18,0.28$ and 0.34 at three values of tip clearance, viz. $\tau=2.2 \%, 5.1 \%$ and $7.9 \%$ of rotor blade height at the exit. Performance tests are carried out for a total of two configurations. From these measurements, partial shroud is found give best performance. The improvement in the compressor performance may be due to the reduction of tip leakage flows by the small extension of partial shroud $(2 \mathrm{~mm}$ on the pressure surface side). The axial distribution of static and total pressure coefficient at rotor exit for the four flow coefficients, clearly indicate increase in total pressure in the rotor tip region for the configuration with PS compared to that for the basic configuration (without PS). Similar increase is observed in the static pressure distribution at the rotor exit for the higher values of clearance. The mass averaged total and static pressures at the rotor exit for both configurations at the three values of tip clearances clearly show that partial shrouds are beneficial in improving the pressure rise of the compressor.
\end{abstract}

Copy Right, IJAR, 2017,. All rights reserved.

\section{Notation:-}

$\mathrm{C}_{\mathrm{u}}=$ Tangential velocity $\quad \mathrm{m}=$ Non-dimensional meridional distance

$\mathrm{P}_{\mathrm{S}}=$ Static pressure $\quad \mathrm{P}_{\text {atm }}=$ Atmospheric pressure

$\mathrm{P}_{\mathrm{O}}=$ Total pressure $\quad \mathrm{R}=$ Non-dimensional radius

$\mathrm{u}_{2}=$ Rotor tip speed $=\left(\pi \mathrm{d}_{2} \mathrm{~N} / 60\right)(\mathrm{m} / \mathrm{s}), \mathrm{x}=$ Non-dimensional axial distance

$\phi=$ Flow coefficient $\quad \rho=$ Density of air $\left(\mathrm{kg} / \mathrm{m}^{3}\right)$

$\tau=$ Tip clearance

\begin{tabular}{|c|c|}
\hline$\psi_{\mathrm{o}}=$ & Total pressure coefficient $=2 \mathrm{P}_{\mathrm{o}} / \mathrm{U}_{\mathrm{U}}{ }^{2}$ \\
\hline$\psi_{\mathrm{s}}=$ & Static pressure coefficient $=2 \mathrm{P}_{\mathrm{s}} / \mathrm{U}_{\mathrm{U} 2}{ }^{2}$ \\
$\gamma$ & \multicolumn{2}{l}{ Power coefficient }
\end{tabular}


$\eta=$ Efficiency (defined in the text)

Superscript:

Circumferentially averaged quantity = Mass averaged quantity

Subscript:

$\begin{array}{ll}\text { 1. Inlet of compressor } & \text { 2. Outlet of compressor }\end{array}$

\section{Introduction:-}

The tip leakage flow thus would have dominant effect on the performance of a compressor. A comprehensive review of tip clearance effects in centrifugal compressors is given by Pampreen (1983). Senoo and Ishida (1987) gave analytical expression to quantify the tip clearance effects in centrifugal blowers Hayami (1997) has found from his experiments that axial movement of the casing has better efficiency over the movement of casing in radial and axial directions. Tip clearance in centrifugal compressor causes the leakage of high pressure fluid from pressure surface to suction surface of the impeller blade, making the flow field highly complex and effecting the performance. The tip clearance studies are conducted to understand the flow behavior in order to minimise the effect of tip clearance. Pampreen (1973), Mashimo et al. (1979), Sitaram and Pandey (1990) have conducted experimental studies and suggested that by reducing the tip clearance gap size, the tip clearance effect can be minimised. The required tip clearance can be obtained by shifting the casing in radial or axial or combined radial and axial directions.

\section{Computational Details and Methodology:}

Table 1:- Design Details of the Rotor

Rotor

\begin{tabular}{|c|c|c|c|}
\hline Total pressure rise, $\Delta \mathrm{p}$ : & \multicolumn{2}{|c|}{$300 \mathrm{~mm} \mathrm{WG}$} & \\
\hline Volume flow rate, $\mathrm{V}$ : & \multicolumn{2}{|c|}{$1.12 \mathrm{~m}^{3} / \mathrm{s}$} & \\
\hline Speed of rotation, $\mathrm{N}$ : & \multicolumn{2}{|c|}{$2000 \mathrm{rpm}$} & 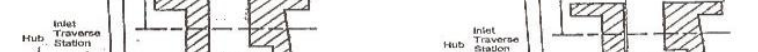 \\
\hline Shape number, $\mathrm{N}_{\mathrm{sh}}:$ & 0.092 & & 1 \\
\hline No. of rotor blades, Z: & 16 & & \\
\hline Inducer hub diameter, $\mathrm{d}_{1 \mathrm{~h}}$ : & \multicolumn{2}{|c|}{$160 \mathrm{~mm}$} & \\
\hline Inducer tip diameter, $\mathrm{d}_{1 \mathrm{t}}:$ & \multicolumn{2}{|c|}{$300 \mathrm{~mm}$} & \\
\hline Rotor tip diameter, $\mathrm{d}_{2}$ : & \multicolumn{2}{|c|}{$500 \mathrm{~mm}$} & \\
\hline Blade height at the exit, $\mathrm{h}_{2}$ : & \multicolumn{2}{|c|}{$34.74 \mathrm{~mm}$} & \\
\hline Blade angle at inducer tip, $\beta_{1 \mathrm{t}}$ : & $35^{\circ}$ & & \multirow{4}{*}{$\begin{array}{l}\text { Basic Configuration Configuration with PS } \\
\text { Fig. 1:- Details of Configurations }\end{array}$} \\
\hline Blade angle inducer hub, $\beta_{1 \mathrm{~h}}$ : & \begin{tabular}{l|l}
$:$ & $53^{\circ}$ \\
\end{tabular} & & \\
\hline Blade angle at exit, $\beta_{2}:$ & a) At hub: & $75^{\circ}$ & \\
\hline (b) At mean section: $90^{\circ}$ & (c) At tip: & $105^{\circ}$ & \\
\hline
\end{tabular}

All the angles are measured w. r. t. tangential direction

Partial Shroud:- The partial shrouds are made of stainless steel of $0.1 \mathrm{~mm}$ thickness. The stainless steel sheet is cut to the shape of rectangle pieces of $50 \mathrm{~mm}$ x $5 \mathrm{~mm}$ size. These rectangle pieces are attached to the tip of the blades using araldite. The configurations tested (basic configuration without partial shroud and configuration with partial shroud) are shown in Fig. 1.
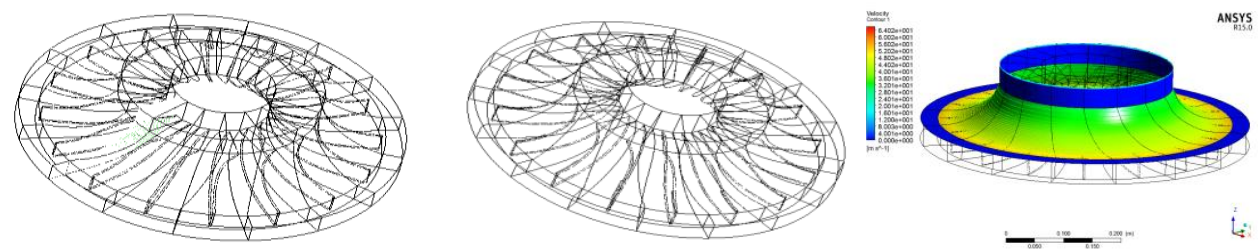

Fig. 2:- Centrifugal compressor without and with partial shroud 

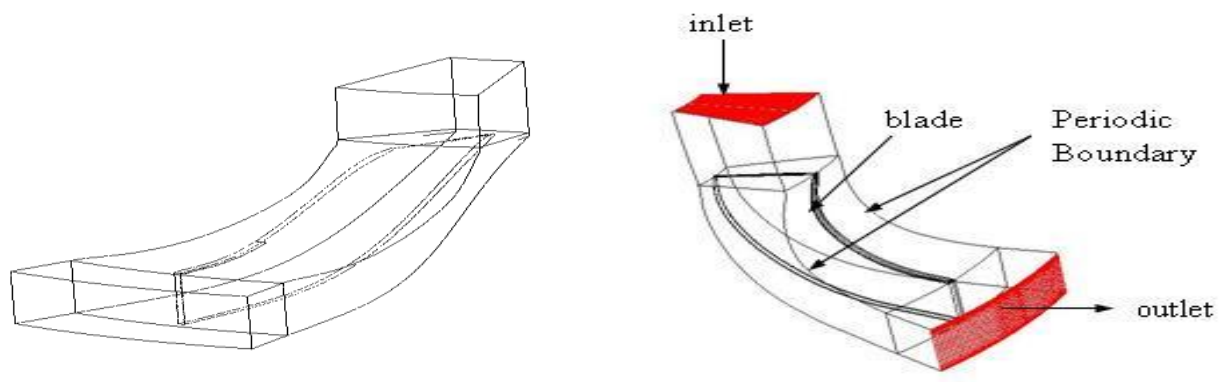

Fig. 3:- Computational domain of single passage with and without partial shroud.

Geometry and mesh: The geometric model used for the computational simulation of impeller with PS and without PS configuration consists of single passage impeller blades. These are done with the assumption that flow is periodic in each vane passage. This avoids the necessity of modeling the entire centrifugal compressor stage thereby saving enormous computational time and resources. The geometric model used for the computational simulation of Centrifugal impeller with above specifications with $2 \mathrm{~mm}$ thickness throughout the blade for generation of three dimensional blades was done as shown in Fig.2. A single passage of the impeller with inlet at $50 \mathrm{~mm}$ ahead of the impeller and outlet at a distance of $35 \mathrm{~mm}$ downstream of impeller is shown in Fig. 3. Casing is designed with $0.7 \mathrm{~mm}$ clearance throughout the blade height. Three tip clearances of $2.2 \%, 5.1 \%$ and $7.9 \%$ of trailing edge blade height are obtained by moving the casing axially. ANSYS CFX 15.0 version software is used for obtaining the solution and standard the SST $k-\omega$ model was applied to obtain turbulent quantities, assuming that the flow in the compressor is fully turbulent. The design rotational speed was 2000rpm. The total pressure, total temperature, and flow direction were specified at the impeller inflow boundary $(P 01=101300 \mathrm{~Pa}$ and $T 01=288.15 \mathrm{~K})$, and the mass flow rate was specified at the diffuser outflow boundary. In CFX we have to use turbo mode for this problem statement, with respective to this stationary, rotating components are defined. The density going to vary compressible fluid with pressure fluid properties kept as air ideal gas. Rotating domain interface used as Stage. The stage averaging at the frame change interface incurs a one-time mixing loss. Physical Time scaling value was observed to be taken as $10^{-3} \mathrm{~s}$. Accuracy criteria of RMS solution was decreased to $10^{-5}$ for better accuracy.

\section{Validations for tip clearance:-}

Prior to comparing the performance of the test cases, the numerical result for the three values of tip clearances $(\tau=2.2 \%, 5.1 \%$ and $7.9 \%)$, was validated with the experimental data. Experimental results were validated by comparing the computed characteristic curves of the efficiency and energy coefficient with the experimental data, static pressure coefficient, and total pressure coefficient, mass-averaged static and total pressures at outlet of the blade with the computational data. The CFD results showed satisfactory agreement with the experimental results over the full range of operating conditions. The overall flow structure predicted by the numerical simulations, including the jet-wake flow pattern, was qualitatively well captured, as observed by comparison with the experimental results. Improved results may be obtained with PS.

\section{Results And Discussions:-}

PERFORMANCE CHARACTERISTICS: Effect of Configuration: The result of the computational investigations revealed that Figure 4 shows the performance characteristic in terms of efficiency, $\eta$ vs. flow coefficient, $\phi$ for four flow coefficients $\varphi=0.12,0.18,0.28$ and 0.34 and at the tip clearance $\tau=2.2 \%$, for both configurations. At the value $\tau$ $=2.2 \%$, of tip clearance, PS gives higher value of efficiency compared to that without PS due to reduced tip leakage flows. In fact the efficiency of the rotor with PS even at the highest value of tip clearance observed is higher than the efficiency of the rotor without partial shroud at the lowest value of tip clearance. Experimental and Simulation results can be concluded that partial shroud is very beneficial to the performance of the compressor. In the present both investigations, partial shroud with a very small extension of $2 \mathrm{~mm}$ on the pressure surface side of the impeller blade is provided. The effect of the two configurations on the performance of the centrifugal compressor in Figure 5 shows the performance characteristic in terms of energy coefficient, $\psi$ vs. flow coefficient, $\phi$ for the three values of tip clearance $\tau=2.2 \%, 5.1 \%$ and $7.9 \%$ for the both configurations. The value of $\phi$ where $\psi_{\max }$ occurs is reduced, thereby increasing stable operating range. 


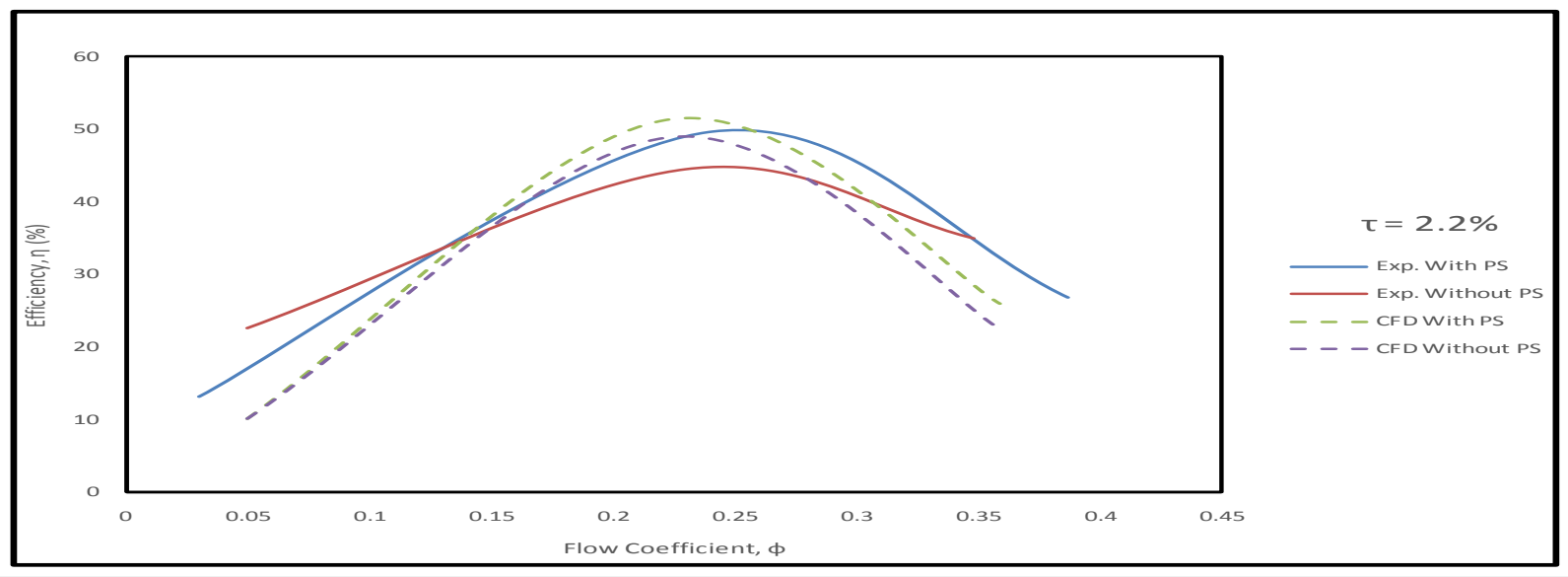

Fig. 6:- Performance of the centrifugal compressor: $\eta$ vs. $\phi$

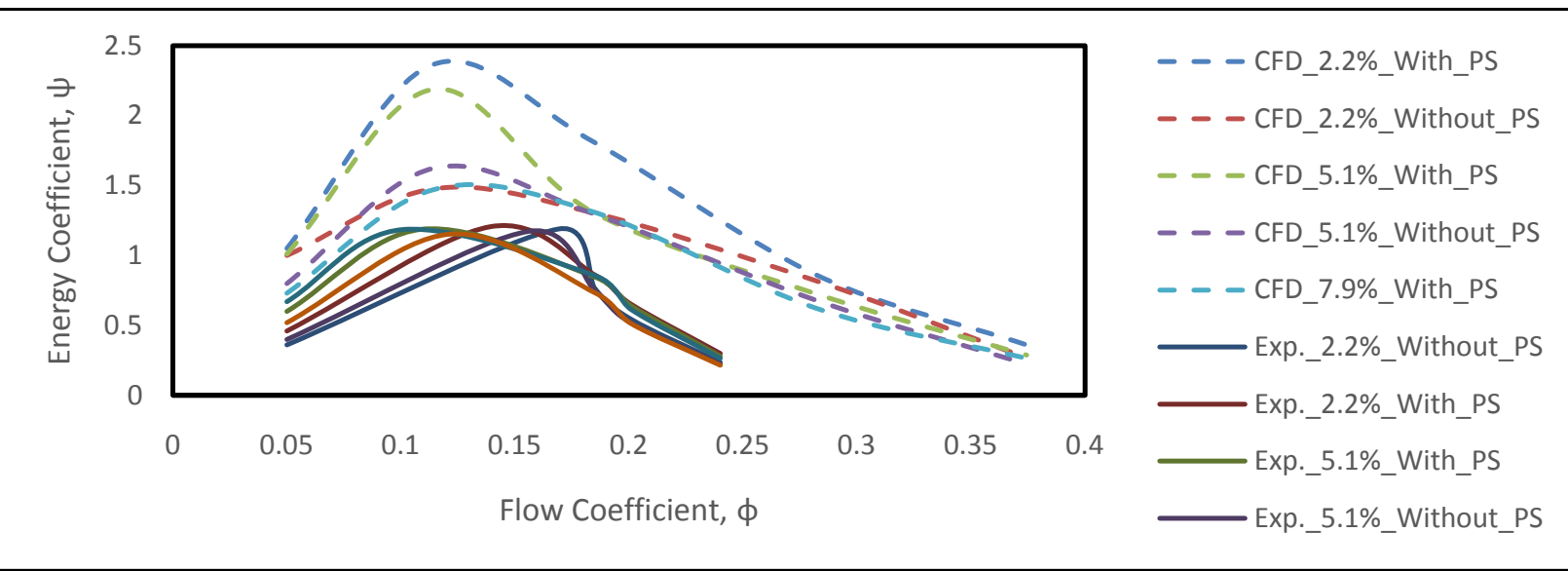

Fig. 5:- Performance of the centrifugal compressor: $\psi v v . \phi$

Impeller Exit Flow Measurements

Total Pressure Coefficient, $\psi_{02}$

Distribution of total pressure coefficient at the rotor exit for both configurations for four flow coefficients $\varphi=0.12$, $0.18,0.28$ and 0.34 and for the three values of tip clearance $\tau=2.2 \%, 5.1 \%$ and $7.9 \%$ for both configurations is shown in Fig. 6. From the figure, it can be clearly seen that rotor with partial shroud (PS) shows increased total pressure coefficient, compared to basic configuration for all the flow coefficients at the tip clearance $(\tau=2.2 \%)$. From the figure, it can be seen that the extent of region of improvement increases with reduction in flow coefficient. That means the higher the loading more is the benefit due to the partial shroud. For the tip clearance $\tau=5.1 \%, 7.9 \%$ the benefits of PS are reduced. For all the flow coefficients it is seen that the total pressure coefficient decreases with increase in tip clearance. At larger flow coefficients the reduction in total pressure coefficient with tip clearance is high. It can also be observed that, the total pressure coefficient increases as the flow coefficient decreases for all the tip clearances. From the figure, it can be seen that the exit of region of improvement increases with reduction in flow coefficient. At larger flow coefficients the reduction in total pressure coefficient with tip clearance is high. The total pressure coefficient difference for $2.2 \%$ to $7.9 \%$ tip clearance is increasing with flow coefficient increase. 


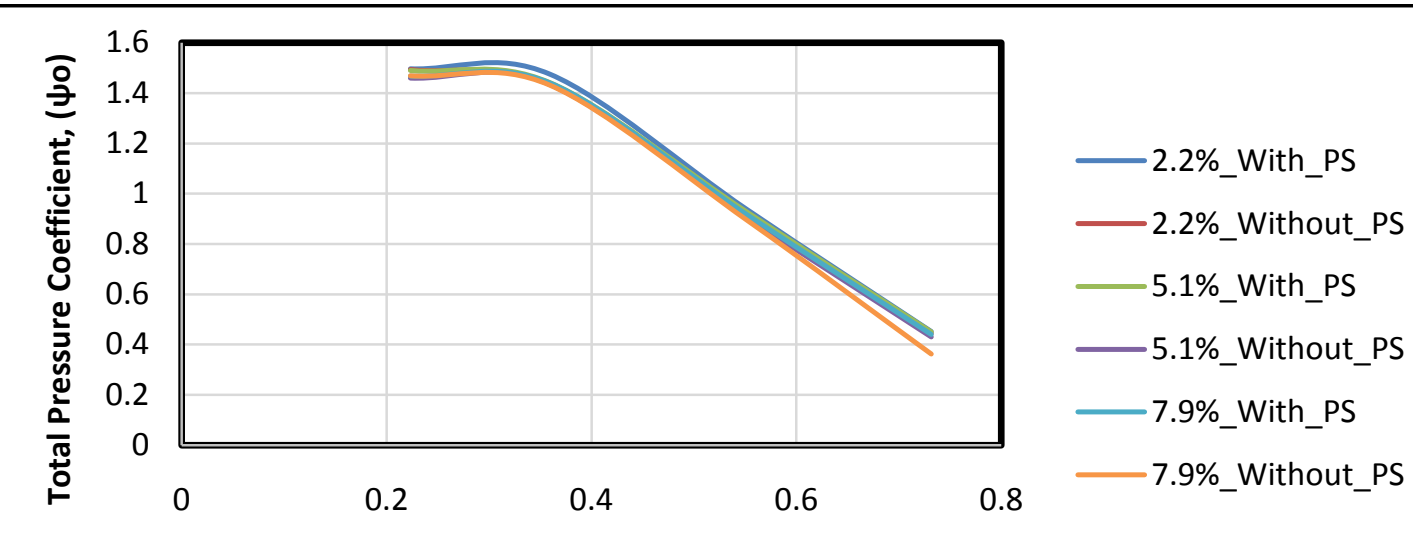

Flow Coefficient, ( $\phi)$

Fig. 6:- Total Pressure coefficient variation at the impeller exit

\section{Static Pressure Coefficient, $\psi_{s_{2}}$}

The static pressure coefficient distribution at the impeller exit for four flow coefficients $\varphi=0.12,0.18,0.28$ and 0.34 and for the three values of tip clearance $\tau=2.2 \%, 5.1 \%$ and $7.9 \%$ for both configurations is shown in Figs.7. From this figure, it can be clearly observed that impeller with partial shroud (PS) shows increased static pressure coefficient, compared to basic configuration for all the flow coefficients at the three values of tip clearances $(\tau=2.2 \%, 5.1 \%$ and $7.9 \%)$. Static pressure for a larger extent from the shroud, as the flow coefficient decreases. It can also be observed that, the static pressure coefficient is increasing as the flow coefficient increases for all the tip clearances. This may be attributed to the partial shrouds attached to the tip of the blades restricting the tip leakage flow. Trend of the static pressure coefficient is almost same for both configurations at three values of tip clearances. The static pressure coefficient drop with increment in tip clearance is more for higher flow coefficient.

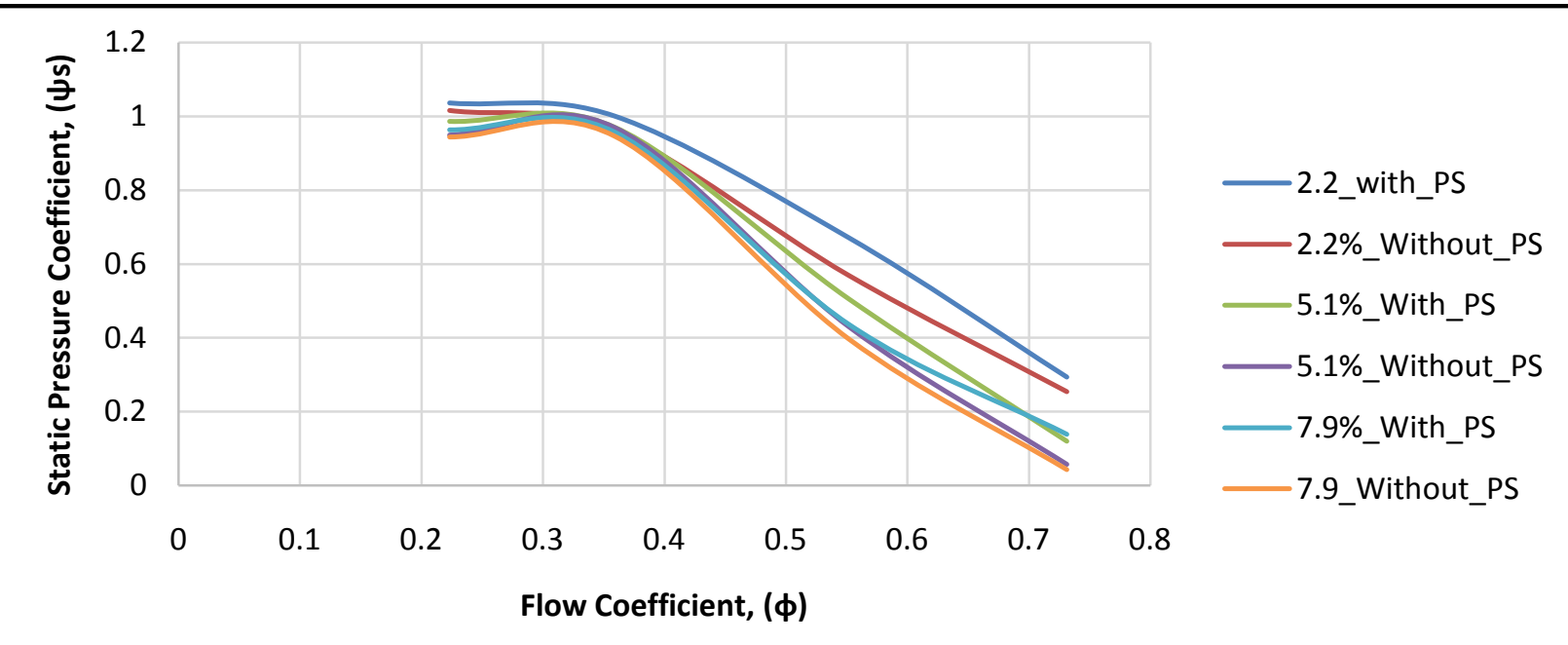

Fig. 7:- Static Pressure coefficient variation at the impeller exit.

\section{Mass Averaged Flow Performance Of Impeller:-}

The mass averaged values of total pressure coefficient $\left(\bar{\Psi}_{O}\right)$ and static pressure coefficient $\left(\bar{\Psi}_{\mathrm{S}}\right)$ at the rotor exit for four flow coefficients $\varphi=0.12,0.18,0.28$ and 0.34 and for the three values of tip clearance $\tau=2.2 \%, 5.1 \%$ and $7.9 \%$ for both configurations is show in figure 8. In the present both investigations, partial shroud with a very small extension of $2 \mathrm{~mm}$ on the pressure surface side of the impeller blade is provided at the tip of the blade region along the axial direction away from the shroud was over analyzed by CFD due to a higher intensity tip clearance flow. The static pressures over the entire operating range for all blades with partial shroud reduced tip clearances were higher than those in the basic configuration case, indicating that reductions in the tip clearance at the tip of the blade 
improved the static pressure rise. The exit of the impeller total pressure also increased for the impellers with reduced tip clearances. With partial shroud had the highest static and total pressures as compared with the basic configuration, because the tip clearance was reduced at the tip of the blade.

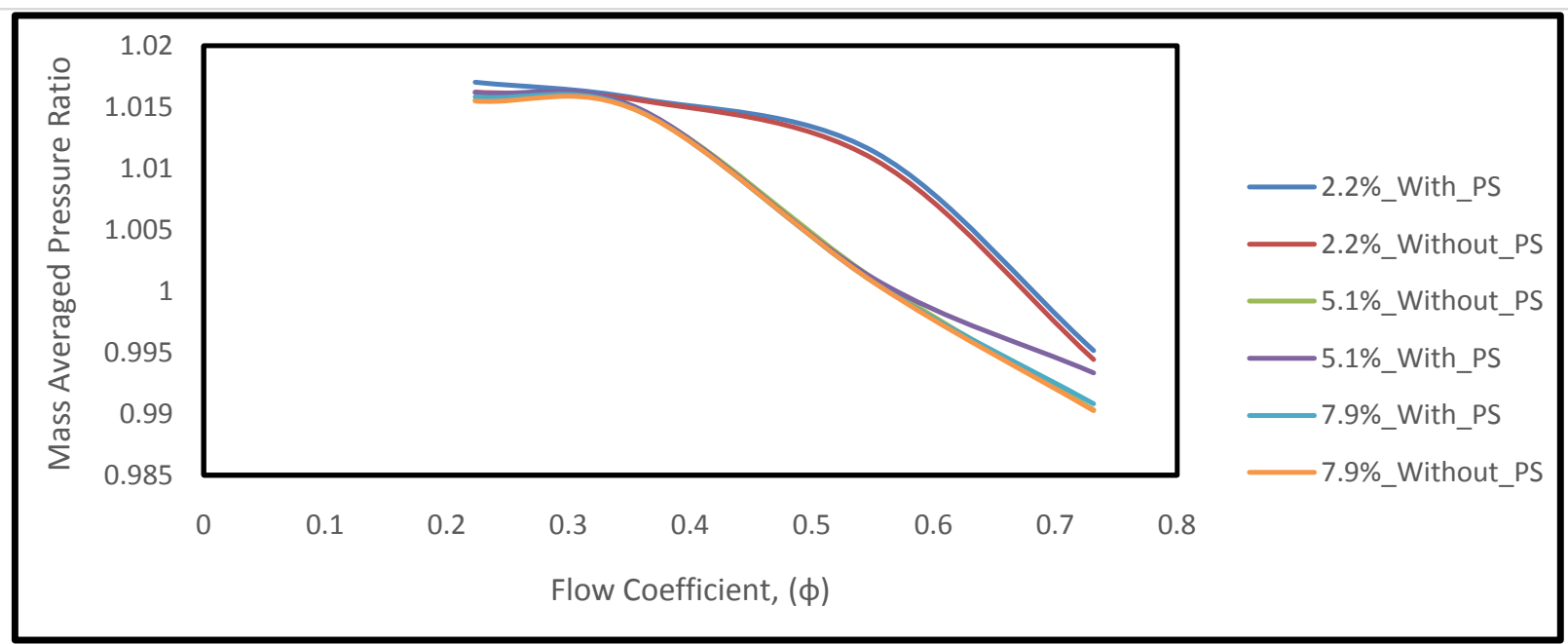

Fig. 8:- Mass averaged performance

Static pressure Contours at Meridional Plane:-

Pressure contours at a meridional plane for four flow coefficients $\varphi=0.12,0.18,0.28$ and 0.34 and for the tip clearance $\tau=2.2 \%$ for both configurations is shown in figure 9. The contours show high pressure on pressure side (PS) of the blade, low pressure on suction side (SS) of the blade. Fluid flow with PS on tip of the blade a slight pressure drop is observed on suction side. Fluid flow without PS on tip of the blade, significant reduction in pressure on suction side is observed.
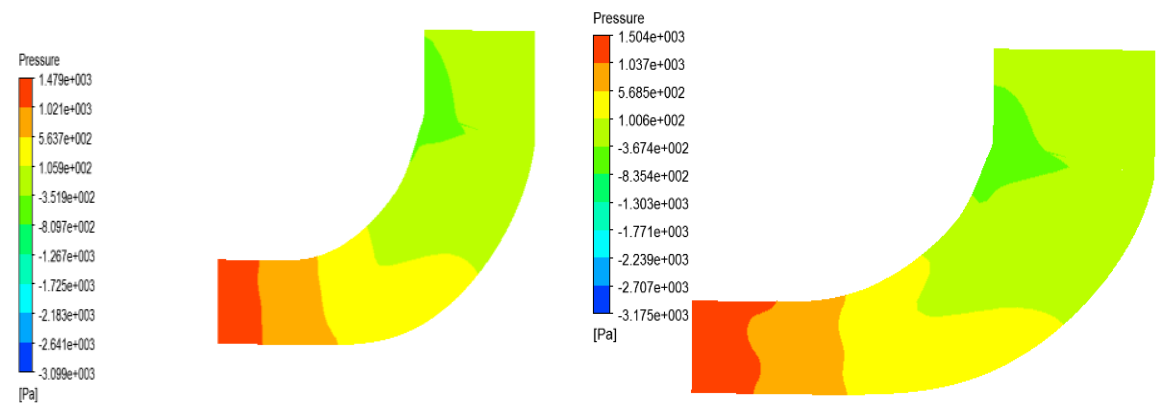

Fig. 9:- Static Pressure contours at Meridional Plane for the tip clearance $\tau=2.2 \%$ at without and with PS at mass flow rate $0.087 \mathrm{~kg} / \mathrm{sec}$.

Total Pressure Contours at Meridional Plane:-

Total pressure contours on meridional plane for four flow coefficients $\varphi=0.12,0.18,0.28$ and 0.34 and for the tip clearance $\tau=2.2 \%$ for both configurations is shown in figure 10. Fluid flow without PS on tip of the blade, on suction side near tip region, low total pressure area caused due to passage wake is observed. With PS on tip of the blade, low total pressure area of passage wake is reduced. The leakage flow from the PS is interacting with passage wake. With PS on tip of the blade for $2.2 \%$ clearance, total pressure is higher at pressure side shroud corner due to the rotation and meridional curvature and low total pressure is observed near the suction side shroud corner because of the boundary layer on stationary domain. 

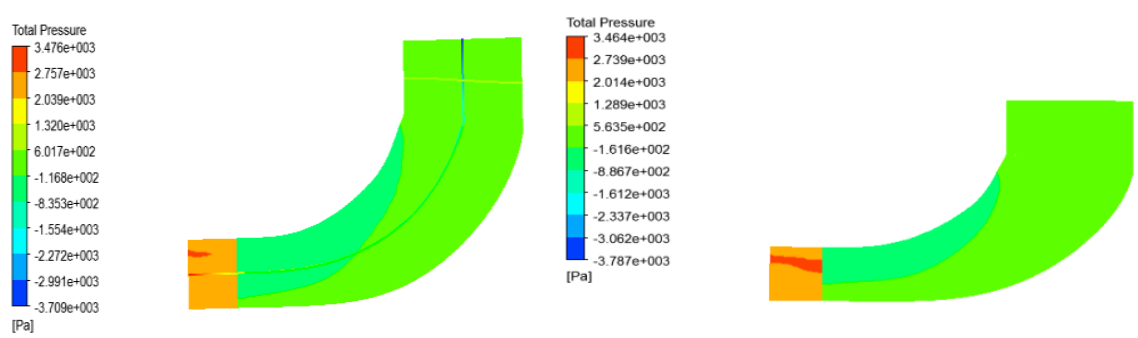

Fig. 10:- Total Pressure contours at Meridional Plane for the tip clearance $\tau=2.2 \%$ at without and with PS at mass flow rate $0.087 \mathrm{~kg} / \mathrm{sec}$.

Velocity Contours at Meridional Plane:-

Velocity contours on meridional plane for four flow coefficients $\varphi=0.12,0.18,0.28$ and 0.34 and for the tip clearance $\tau=2.2 \%$ for both configurations is shown in figure 11. The contours show improved velocities on suction side with PS. The low velocity passage wake area on suction side of the blade is reducing with without PS on tip of the blade. However, the velocity in passage wake region is much lower with without PS on tip of the blade as more leakage flow is interacting with the main flow.
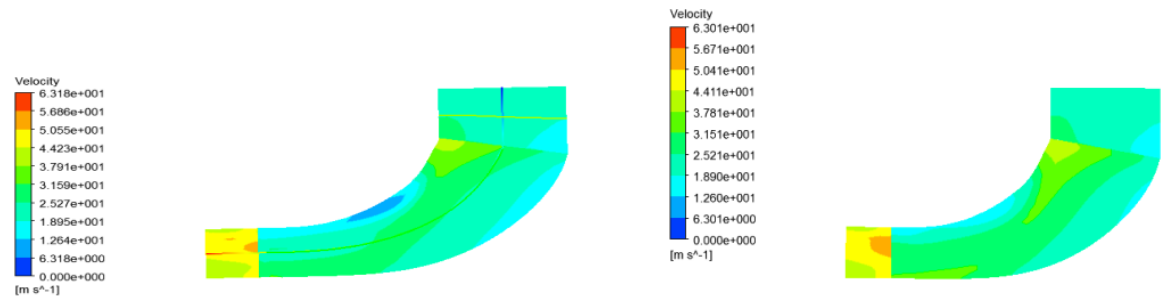

Fig. 11:- Velocity contour on meridional plane for the tip clearance $\tau=2.2 \%$ at without and with PS at mass flow rate $0.087 \mathrm{~kg} / \mathrm{sec}$.

\section{Velocity Vectors at Meridional Plane:-}

Velocity vectors on meridional plane for four flow coefficients $\varphi=0.12,0.18,0.28$ and 0.34 and for the tip clearance $\tau=2.2 \%$ for both configurations is shown in figure 12. Passage wake with low velocity is observed on suction side near casing of the blade. With PS on tip of the blade, reduction in passage wake area is observed. Fluid flow with PS on tip of the blade for $2.2 \%$ tip clearance, a circulating flow near the suction surface is observed due the strong centrifugal forces. For other clearances, wake growth is altering the flow pattern. At higher clearances, increase in leakage flow observed.

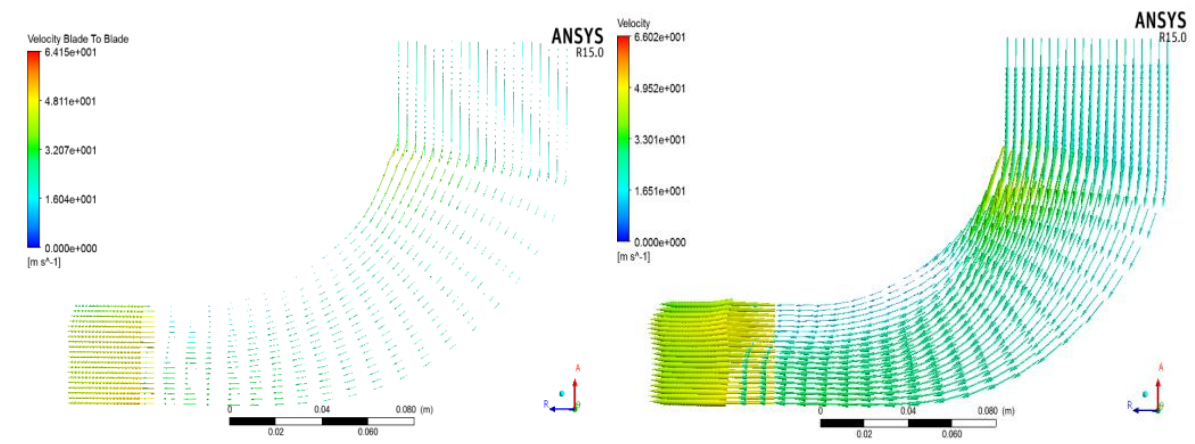

Fig. 12:- Velocity vectors on meridional plane for the tip clearance $\tau=2.2 \%$ at without and with PS at mass flow rate $0.087 \mathrm{~kg} / \mathrm{sec}$.

\section{Velocity Vectors at Outlet:-}

A velocity vector at the exit of the impeller for four flow coefficients $\varphi=0.12,0.18,0.28$ and 0.34 and for the tip clearance $\tau=2.2 \%$ for both configurations is shown in figure 13. The fluid flows with PS on tip of the blade velocities are high on suction surface than pressure surface because of blade curvature. With increase in tip clearance, the velocity on both pressure side and suction side is decreasing. For $2.2 \%$ and $5.1 \%$ clearance, high velocity of the fluid above the blade from pressure side to suction side through tip clearance is clearly seen. 


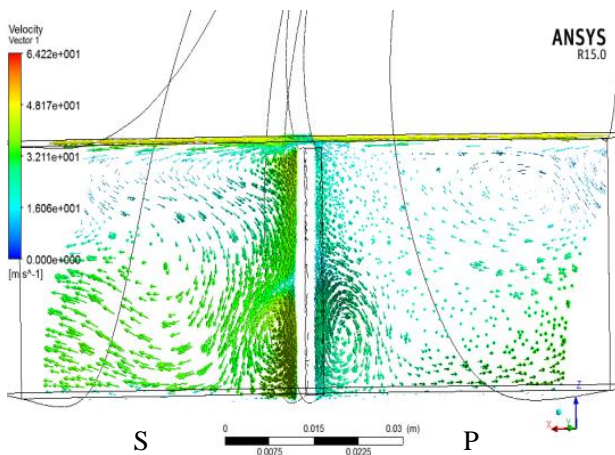

S

-

Fig. 13:- Velocity vectors at exit of the biade for $2.2 \%$ tip cle;

\section{Blade loading chart:-}

$0.087 \mathrm{~kg} / \mathrm{sec}$.

Blade loading curve for $2.2 \%$ tip clearance at without PS and with PS were shown in figure 14. Fluid flow without PS and with PS on tip of the blade, significant change in pressure on suction side is observed. Low static pressure on suction and high pressure on pressure side of the blade is observed. With increase in tip clearance for $2.2 \%$ to $7.9 \%$, static pressure on both pressure side and suction side are reducing.
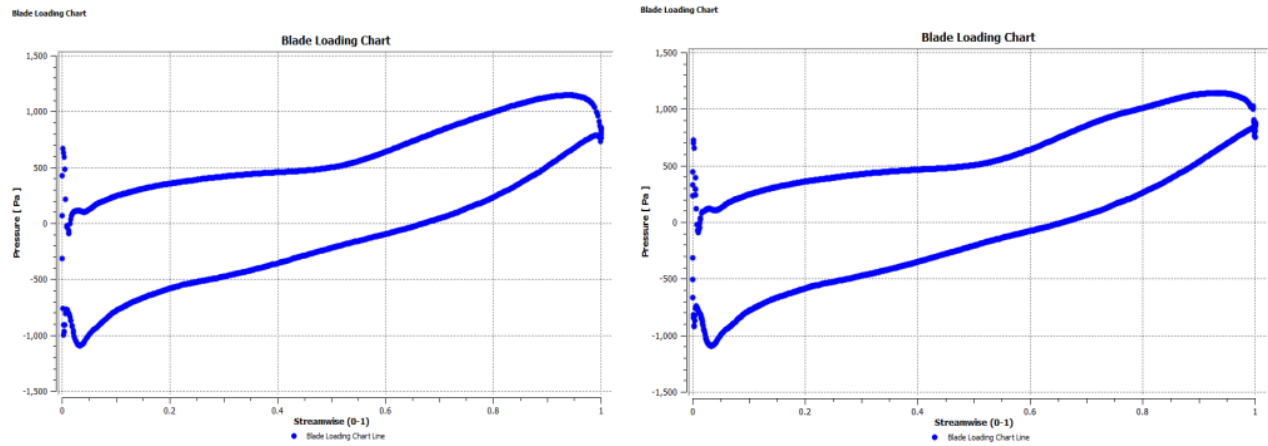

Fig.14: Blade loading for $2.2 \%$ clearance at without and with partial shroud at mass flow rate $0.087 \mathrm{~kg} / \mathrm{sec}$.

\section{Conclusions:-}

A low speed centrifugal compressor for four flow coefficients $\varphi=0.12,0.18,0.28$ and 0.34 and for the three values of tip clearance $\tau=2.2 \%, 5.1 \%$ and $7.9 \%$ for both configurations are analysed. The results are compared with the without partial shroud. With partial shroud on tip of the blade, velocity at the meridional section at with the partial shroud is increased; the pressure at outlet is reduced because of more leakage of flow with the basic configuration. With partial shroud on tip of the blade, flow passage wake, the velocity and total pressure improvement is observed. Also with partial shroud on tip of the blade, static pressure rise at outlet is observed for all coefficients.

\section{References:-}

1. Takemura, T. and Goto,A.(1996), "Experimental and numerical study of three-dimensional flows in a mixed-flow pump stage", ASME Journal of Turbomachinery,

2. $118,552-561$.

3. R. J. Moffat, "Describing the uncertainties in experimental results," Experimental Thermal and Fluid Science, vol. 1, no. 1, pp. 3-17, 1988.

4. Tang, J., Turunen-Saaresti, T. and Larjola, J., 2008, "Use of partial shrouded impeller in a small centrifugal compressor", J. of Thermal Sci., Vol. 17, No. 1, 2008, pp. 21-27.

5. Akturk, A. and Camci, C., 2010, "Axial flow fan tip leakage flow control using tip platform extensions", ASME J. Fluids Engg., 132 (5), 051109-1 to 10.

6. Akturk, A. and Camci, C., 2011, "Tip clearance investigation of a ducted fan used in VTOL UAVs, Part 1: Baseline experiments and computational validation”, Proc. ASME Turbo Expo 2011, Paper no. GT2011-46356.

7. Akturk, A. and Camci, C., 2011, "Tip clearance investigation of a ducted fan used in VTOL UAVs, Part 2: Novel treatments via computational design and their experimental validation”, Proc. ASME Turbo Expo 2011, Paper no. GT2011-46359.

8. Kameier, F. and Neise, W., 1997, "Experimental study of tip clearance losses and noise in axial turbomachines and their reduction”, ASME J. of Turbo., 119(3) 460-471. 